\title{
Soft Trust and mCommerce Shopping Behaviours
}

\author{
Serena Hillman, Carman Neustaedter, John Bowes, and Alissa Antle \\ School of Interactive Arts and Technology, Simon Fraser University \\ 250-13450 102 Avenue, Surrey, British Columbia, Canada \\ shillman@sfu.ca, carman_neustaedter@sfu.ca, bowes@sfu.ca, aantle@sfu.ca
}

\begin{abstract}
Recently, there has been widespread growth of shopping and buying on mobile devices, termed mCommerce. With this comes a need to understand how to best design experiences for mobile shopping. To help address this, we conducted a diary and interview study with mCommerce shoppers who have already adopted the technology and shop on their mobile devices regularly. Our study explores typical mCommerce routines and behaviours along with issues of soft trust, given its long-term concern for eCommerce. Our results describe spontaneous purchasing and routine shopping behaviours where people gravitate to their mobile device even if a computer is nearby. We found that participants faced few trust issues because they had limited access to unknown companies. In addition, app marketplaces and recommendations from friends offered a form of brand protection. These findings suggest that companies can decrease trust issues by tying mCommerce designs to friend networks and known marketplaces. The caveat for shoppers, however, is that they can be easily lured into a potentially false sense of trust.
\end{abstract}

\section{Author Keywords}

Mobile; commerce; trust; shopping

\section{ACM Classification Keywords}

H.5.2 [User Interfaces]: User-Centered Design

\section{INTRODUCTION}

As a culture we are now seeing a large uptake of mobile devices that expand the ways in which people connect with and obtain information. This trend has resulted in an increasing number of opportunities for people to shop for and purchase items online using mobile devices such as smartphones, e-readers, tablets, etc. This activity is called mobile Commerce or mCommerce for short [20]. The growth of mCommerce is noted by many companies $[1,3,12,13]$. For example, Paypal reports that it processes up to $\$ 10$ million dollars in mobile payments a day and predicts $\$ 3$ billion in mobile payments in 2011 [12]. While

Permission to make digital or hard copies of all or part of this work for personal or classroom use is granted without fee provided that copies are not made or distributed for profit or commercial advantage and that copies bear this notice and the full citation on the first page. To copy otherwise, or republish, to post on servers or to redistribute to lists, requires prior specific permission and/or a fee.

MobileHCI'12, September 21-24, 2012, San Francisco, CA, USA.

Copyright 2012 ACM 978-1-4503-1105-2/12/09...\$10.00. there has been a large amount of research on eCommerce $[6,8,14]$ there has been comparatively very little that focuses on understanding mCommerce. This gap is important as mCommerce is not a simple extension of eCommerce. "mCommerce has its own technological infrastructure, new business models and value chain, and new value for consumers. Hence, it requires new thinking for its dissemination and adoption" [11].

Our own interest in the topic was twofold. First, we were interested in understanding the everyday routines of people who perform mCommerce activities to learn what people shop for, when they shop, and how they feel about shopping on mobile devices. Second, we wanted to focus in on the topic of trust and explore how mobility and the use of mobile devices affects issues of trust amongst shoppers. In the past, a lack of consumer trust has been cited as a major barrier to the adoption of eCommerce [25] and researchers have even developed trust models to understand and address buyer concerns [8,25]. We wanted to understand how such models might extend to mCommerce, if at all.

To address this, we conducted an exploratory study of mCommerce activities where 17 participants recorded their mobile shopping activities in an online daily journal for three weeks. Following this, we conducted semi-structured interviews with them to further understand their routines and, specifically, issues or moments related to trust in their mCommerce activities. Here we focused on issues of "soft" trust (e.g., willingness to make a transaction, knowledge of companies) [6], as opposed to "hard" trust (e.g., encryption) $[6,14]$, in order to limit the scope of our study. Surprisingly, given the large volume of eCommerce literature on trust issues, our results show that users do not often have soft trust issues as it relates to their mCommerce activities. This is because app marketplaces (e.g., the Apple App Store) lend brand protection, users' friends make shopping recommendations, the social web ranks, reviews and policies, and large brands dominate other mediums to provide a level of perceived trust for mobile shoppers. The challenge following from this is that mobile shoppers may be lead into a (potentially) false sense of security.

Our paper unfolds as follows. First, we talk about related work on mobile device usage, eCommerce, and frameworks for understanding trust. Second, we outline our diary and interview study methodology. Third, we detail the main 
findings from our study. We conclude by discussing the importance of our findings for the design of mCommerce applications and devices to support them.

\section{RELATED WORK}

\section{eCommerce and Trust}

People commonly shop for any and all things online, though some people are less likely to adopt online shopping behaviours than others [8]. A common assumption is that consumers are vulnerable and likely to expose themselves to loss if they provide personal information during an online purchase transaction [6]. Thus, one of the main focal points of eCommerce research is trust; it is one of the main factors that affect whether or not people engage in eCommerce activities and to what extent [8].

Trust is a complex term. Researchers typically describe trust as being based around: predictability, reliability, fairness, benevolence and integrity [5]. Social exchange theory shows that people make social decisions based on perceived costs and benefits, trying to maximize benefits and minimize costs [8]. For eCommerce, if the perceived risk is low enough, people will purchase products online [8]. Trust is commonly divided into two categories for commerce activities. First, hard trust is based around technical solutions and secure interactions with the belief that data will be transmitted and encryption and firewalls can protect customer information [6]. Second, soft trustthe focus of our study - is centered around the privacy of personal information and vendors' quality of service [6]. This type of trust normally cannot be resolved through the application of back-end technology such as new encryption methods, data transfer protocols, etc. [9].

There are several factors that make it difficult for online companies to develop trust with their customers as compared to in-person stores. Typically online stores are easier to quickly create; consumers are not able to view a company's investment in buildings and personnel; consumers are unable to physically evaluate products in an online environment; and, online stores often lack human elements and interaction [6].

Zucker developed three types of Trust Production Mechanisms [25] which Luo [8] subsequently extended in eCommerce. First, characteristic-based trust relies on similarities between consumers and companies in order to establish trust (e.g., similar sex, ethnicity, or affiliations) [8, 25]. Second, Process-based trust refers to trust that is built through a history of past transactions [25]. Luo describes it as a form of gift-giving and sharing of information that is especially important in the business-to-business (B2B) world [8]. For example, companies often create and distribute 'white papers' to promote their company [8]. Third, institutional-based trust is deliberately intended to build trust in the holder's ability, integrity and intentions [5, 25]. This is done through third party guarantors such as universities with certified education, associations with professional conduct standards, and medical and law licenses to guarantee ethical practice $[5,8,25]$.

\section{Mobile Device Usage}

Turning to mobile device usage, we see that people use mobile devices in a variety of situations and for different purposes. Using a diary and interview study, Nylander et al. [15] explored the use of mobile phones and found that they were most often used in the home (31\% of the time), in addition to outdoors $(23 \%)$, in transit $(23 \%)$, indoors $(16 \%)$, and at work (8\%). Most surprisingly, more than $50 \%$ of their participants used their mobile phones to access the Internet even though they had access to a computer that was close-by [15]. Our study builds on this to understand where and when mCommerce activities occur.

Researchers have also investigated specific instances of mobile device usage that offer important comparisons for our study. Using a voicemail diary, Palen et al. [19] explored the mobile phone practices of new adopters. Results showed that people normally started using mobile phones for reasons of safety, business, or to replace a landline phone; however, usage often migrated to unexpected things such as constant accessibility and microcoordination [19]. O'Hara et al. [16] explored mobile video telephony and found that video calling was often seen as being awkward in public places because other people could easily observe the activity [16]. We explore whether or not the same issue arises for mCommerce activities done in public. O'Hara et al. [19] also explored the consumption of video on mobile devices and found that people would watch videos both in and outside the home despite having computers or televisions nearby [19]. People also watched video on their mobile devices at routine times during their day (e.g., while in transit) and would even turn shared spaces (e.g., a carpool) into a more private place by watching video in a solitary manner [19]. We show how a similar activity occurs for mCommerce. Using a survey and screenshot diary study, Karlson et al. [7] found it was difficult to follow-up (or continue) with uncompleted tasks at a later point, especially if this was done on a different device or computer [7]. Our study builds on this by showing that mCommerce activities do not typically migrate between devices.

The only study that we know of specifically focusing on mCommerce activities was O'Hara and Perry's [18] photo diary and interview study that looked at how users deferred impulsive shopping purchases. Their findings showed that people often needed more information about items before purchase and were unable to get this information. Thus, half of deferred transactions could be further supported by the incorporation of cross-medium information transfer strategies such as QR codes [18]. They also found that deferred transactions resulted because of the social nature of some purchases and a requirement for discussion or asking permission (e.g., asking a partner) before buying. 
Thus, they suggest incorporating social networks in mCommerce design.

In summary, the related work provides a backdrop for understanding trust and eCommerce activities. We also see that mobile activities have been studied in a variety of ways, but there is little specific research on mCommerce. We return to these topics in our Discussion to interpret our findings and compare our work to the related literature.

\section{DIARY \& INTERVIEW STUDY METHODOLOGY}

We conducted a diary and interview study of mobile device shopping and purchasing behaviors and routines, as well as issues of soft trust.

\section{Participants}

We recruited 17 adult participants (9 female) who were regular mobile device shoppers (e.g., purchased online at least once every two weeks). We chose this population because their shopping behaviours and trust issues were less likely to be a result of new user adoption or novelty. Our recruitment strategies included advertising in social media applications, to undergraduate classes, and via email forwarding as a form of snowball sampling. All participants but one was from the same metropolitan city within North America. Participants' ages ranged from 19 to 44 and occupations varied heavily (e.g., students, social workers, designers, salespeople, teachers, administrative assistants, marketers). Only four participants were undergraduate students; we purposely chose to move beyond just studying this distinct population. Participants also ranged in terms of their main mobile device: eight people used an iPhone, three used an iTouch, three used a Blackberry, two used an Android device, and one person used an iPad. In all cases but the iPad, the participant carried the device with them nearly all the time.

\section{Method}

Our study method was deliberately exploratory, despite there being existing knowledge of mobile device routines, eCommerce activities, and trust frameworks. We wanted to explore mCommerce without preconceived notions of what the activity "should" entail. Our focus was also specifically on mobile shopping and not on providing detailed descriptions of eCommerce practice such that one could properly and deeply compare eCommerce to mCommerce. We recognize, however, that what is or is not mCommerce is a bit of a gray area. Historically, mCommerce was defined as shopping on devices with continuous Internet connectivity [24]. Yet with an increasing number of computational devices available in varying sizes and shapes with different levels of 'connection,' this definition is dated. For clarity and focus then, our study looks specifically at shopping on devices that are easy to carry and take with a person (e.g., they are mobile), where they may have either continuous or intermittent Internet connectivity. Thus, our study focuses on shopping on smartphones, tablets, ereaders, and mobile music players (e.g., iPods) with shopping capabilities, but not on computers or laptops. Our study method consisted of two distinct stages.

1. Electronic Diary. We recognized that mobile device activities can take place at various times and places and it can be difficult to directly observe these activities as a result $[7,15,19]$. For this reason, participants first kept an electronic diary of their mCommerce activities over a period of three weeks where we asked them to fill out an online form for each of their mCommerce activities. This included both shopping (without purchasing) and buying. The diary form asked participants to describe their activity, any concerns about trust (where we purposely did not define 'trust'), and their location when the activity occurred. Participants received a daily reminder via email and SMS, encouraging them to visit the e-diary form and enter their mCommerce activity for the day. Participants were also asked to send in a diary entry even if they did not do any shopping activity that day in order to indicate this was the case. To aid in accessibility, participants were asked to install a shortcut on their computer and mobile devices to the diary webpage.

We recognized that participants might not be able to make a diary entry as soon as they participated in a mCommerce activity due to the mobile and likely spontaneous nature of such activities. It was also apparent during test runs of the study that having memory aids were useful when making diary entries. Because of this, participants were encouraged to take a screenshot of their mCommerce activities as they happened in order to capture an in-the-moment visual that could be later used for recollection; this is similar to [7]. Participants could upload screenshots using the diary form.

2. Semi-Structured Interview. Following the three-week diary period, we conducted a semi-structured interview with each participant. The goal of the interview was to expand on the understanding of the activities recorded in each participant's diary, to check the accuracy of entries, and allow participants to voice any other additional insight. Example questions included: what prompted you to perform the activity; what were you doing before/after the activity, were you familiar with the company you purchased or shopped from, did you have any trust concerns, etc. Participants were paid a total of $\$ 40$ for both study stages.

Both the diary entries and interviews took place over the summer months of 2011; thus, they did not span any major holidays known for 'excessive' shopping. As a result, our findings are focused on more 'normal' everyday shopping.

\section{Data Collection and Analysis}

In total, participants completed 161 diary entries that contained mCommerce activities. All participants had at least one activity and the average was 9.5 entries across the three-week span (median 9, range 1 to 20). All interviews were audio recorded in order to review interview data numerous times. We also kept handwritten or typed notes. We inductively analyzed all diary entries along with our 
interview notes using open, axial, and selective coding to draw out the main themes [21] and compare participants.

Next we outline our results focusing on several main themes found in our data. First, we explore mCommerce shopping and purchasing activities to describe what people commonly shop for and purchase. Second, we describe when and where people shop from and why. Third, we explore in detail the trust concerns (or a lack thereof) that participants experienced and the reasons for this.

\section{SHOPPING AND PURCHASING ACTIVITIES}

Participants used their mobile devices for a large variety of mCommerce activities, as shown in Table 1. This was dominated by shopping without purchase (Row 1), followed by the acquisition of software (e.g., apps) (Row 2), the purchase of 'real world' items (Row 3), and bidding/selling items in auctions (e.g., eBay) (Row 4). Some people performed certain activities more than others, yet we did not notice any trends related to specific demographics.

For shopping, participants were looking for particular item at one or more stores (on their mobile device) or comparing prices of an item. In this case, however, there was no purchase. Items varied and included clothing, housing accessories, shoes, car insurance, cellphone accessories, toys, and pet products. Reasons for not purchasing included: a high price, the item or service was not what they were looking for in terms of location, quality, or they were just browsing for fun and nothing 'caught-their-eye.' Most shopping was done within apps created and published by specific stores (e.g., eBay, Amazon). To a much lesser extent, some participants would use their mobile device's web browser to shop on a particular company's website.

Software downloads included a large amount of 'app' downloads for the device itself using the device's marketplace (e.g., Apple App Store) (92\%). Others bought a browser download, OS upgrade, and a podcast.

Participants bought a variety of real world items including movie or sports tickets, food, jewelry, shoes, yoga classes, flowers, ebooks, books, and clothing. 17 participants logged in to a previously created account to make a purchase; this included using Amazon and eBay apps, along with apps made by Social Couponing sites and local food stores. The other 11 participants entered their credit card information from scratch into a web browser page to earn additional credit card points, or because the company did not have an app with recorded payment information.

A breakdown for the cost of items/services/products people shopped for is shown in Table 2. This illustrates that people predominantly shopped for small value items on their mobile devices, but occasionally people did shop for more expensive things. When it came to whether or not people purchased these items, we saw greater than a 76\% percent purchase rate for items under $\$ 5$. Only five of the $25 \$ 30$ $\$ 100$ products were purchased or downloaded. Only two of the \$100-\$350 were purchased or downloaded.

\section{DAILY ROUTINES AND TIMING}

We found that the timing of mobile shopping and purchasing fell into three broad categories. People either shopped spontaneously when the need arose, as a habit or routine, or during fixed time intervals based on schedules.

\section{Spontaneous Mobile Shopping}

Close to half of our participants (8 of 17) were highly spontaneous in their shopping habits. In these cases, participants' shopping and purchasing activities were a response to their external environment and other activities. This included triggers from activities both on and off their mobile device. For example, participants were already out shopping in person and needed to compare prices on

\begin{tabular}{|l|c|}
\hline \multicolumn{1}{|c|}{ Activities } & \% \\
\hline Shopping (no purchase) & $54 \%$ \\
\hline Software Downloads & $26 \%$ \\
\hline "Real World" Items & $17 \%$ \\
\hline Auctioning/Selling & $3 \%$ \\
\hline
\end{tabular}

Table 1. Activities across diary entries

products, they were told that new software updates were available for their device, or they completed certain activities, such as reading a book, which prompted them to shop for and download a new book to read. Because participants carried their mobile device with them nearly all the time and most had constant Internet connectivity, they were able to act on these stimuli in the moment, regardless of their location or time of day. For example, when asked on the diary form why they engaged in each shopping activity, P2's diary described several points in time were other activities were the trigger, both on and off the mobile device:

"While in future shop we were about to purchase a laptop when we thought we saw it at London drugs for cheaper"

"Today I received an email that OS Lion was ready to download and purchase"

P9's diary entries also reflected very spontaneous shopping activities. This included browsing for products based on recommendations from friends (both in person and via online messages), going on a vacation to Seattle and looking for a tourist pass, and looking up board games after a night of playing games with friends.

\section{Shopping as a Habit or Routine}

Just under half of our participants (6 out of 17) were much more routine in their shopping activities. Routines certainly varied across participants, but the fact that shopping activities occurred in a consistent and repeating pattern was 
somewhat surprising. That is, participants had a specific time and place where they shopped on their mobile device, they looked for a specific type of item or specific stores' items, and the behaviour repeated regularly. Shopping was either simply for the sake of having something to do, or it was because the participant had a particular interest in a certain type of item.

Routine shopping was most often reported to occur during public transit rides to or from work or school. In these situations, participants often had 'time to kill' and would shop in these moments of downtime. The mobility of their device and constant Internet connectivity made this possible. For example, 6 of 7 diary entries made by P1 were shopping activities that occurred during the participants' commute from home to work where all occurred within the same two-hour window of time. This is despite the participant feeling that her shopping activities were more spontaneous in nature than routine. While the items purchased may have been spontaneous, the routine nature of the timing of such shopping activities was certainly routine for the participant.

For some participants, the routine act of shopping was tied strongly with checking their email, which was also a routine act done at particular times in the day. For example, P8 recorded eight diary entries, all of which took place while on the train commuting to school in the morning and shortly after the participant checked his email. His diary entries repeated the same scenario over and over:

"I went on the Internet to check my email and saw a daily deal for Groupon"

"While waiting for my train to class, I went on the Internet to check my email and saw the daily deal for Indulge and Groupon"

"Checking email while taking [train] to school this morning. Saw Groupon and Indulge daily deal..."

Other participants were also triggered to shop based on their routine checking of email but these activities occurred at either at home or work where the timing was typically the same each day. This included first thing in the morning, first thing once arriving at work, or in the evening before bed. Email triggers ranged from eBay alerts of daily deals to 'one off' specialty stores' promotions. For example, P17's 15 diary entries all involved the same routine of checking email:

"every morning I wake up, shower and everything, flip through my emails, either first thing in the morning, before I leave for work or first thing when I get to the office ... that is what I do every day, literally, every day ... if something comes in, in the middle of the night, I want to get jump on it and if there is deals within those I share with my friends."

Two participants used their mobile devices to shop at eBay, Amazon, and specific interest stores for collectable items on a regular basis from their work or homes. Here they were interested in specific items as opposed to simply 'filling the time.' This illustrates the more targeted nature of some participants' shopping routines. For example, P15 is an avid collector of pens, inks, and flutes and satisfies his interests by frequently browsing eBay for 'good value' items to add to his collections. The participant talks about shopping during routine times, "it was my usual browsing time after lunch...". P10 was remarkably similar to P15 and frequently shopped on his mobile device on eBay (using its app) and specialty stores. Here the interest was in specialty clothing and occurred at his desk at work (where shopping was done on his mobile device and not the computer) or at home with the majority of activity happening late at night. Several diary entries from P10 illustrate this behaviour:

"decided to check on what's new at Macy's for the Sean John Men's line"

"Quickly checked on eBay to see the Sean John auctions as it has been a while since I last checked"

"Went on to Dr. Jay's to check out the Sean John clothes".

In summary, we see several interesting patterns in these results. First, not all participants are restricting themselves to purchasing in the privacy of their own home. This suggests a lack of concern that others might see their shopping activities, in particular, in places of (often) tight quarters such as public transit. Second, we see the strong tie of mCommerce activities to the routine checking of emails from companies as well as friends. We return to this later as one important factor affecting trust. Also, we saw participants engaging in shopping and purchasing over their mobile devices at home or work even when a personal computer was available and nearby. When at home, the most common location for participating in shopping activities was in bed (e.g., late at night). Participants indicated the mobility of the device allowed for greater ease of use in this location.

\section{Shopping During Fixed Time Intervals}

We also saw that while not necessarily routine, three participants had fixed time intervals when they would shop. That is, they would shop at a certain time, yet they wouldn't do this on a consistent basis and they weren't looking for specific items. These instances were also not spontaneous in nature.

For example, several participants described being at work and having a few spare minutes where they decided to shop online. Their company policy was such that they were not allowed to 'surf' certain websites so, instead, they would use their mobile phone for these shopping activities. Thus, the time interval for shopping was during the participants' work hours, but it didn't occur every workday and there was no particular spontaneous trigger for the activity. It was simply out of a desire to shop.

Another participant would similarly shop in the evening when she was at home after work. This too wasn't a 
recurring routine, but her shopping always occurred at this time and place when it did happen:

"well I suppose I don't really use it to browse (shop) when I am at work, because I just use it for my emails and my work related stuff and then by the time I get home it is about 6:30pm-7:00pm and then by the time I eat it is probably 8pm and that is when I have spare time to mess around and do shopping".

\section{CHARACTERIZING TRUST (AND MISTRUST)}

Overall, participants had few trust concerns when shopping and making transactions on their mobile devices. This was surprising given the concerns people often have for eCommerce [8]. We explore the reasons for this next.

\section{Little Risk}

First, many participants felt that most of their mCommerce activities presented little actual risk to them. Participants who in particular felt there was little risk were not surprisingly those who: spent very little money, mostly only acquired free products or services, or simply shopped as opposed to purchased. For example, P2 and P4 both told us that they had no trust issues because they did not actually purchased anything. P9 elaborates with a very common reaction from participants who just shopped:

"I was just looking at prices and seeing product descriptions so I don't have trust issues associated with that."

P5 similarly told us he had no trust concerns when downloading a podcast because "it's free and no cost is involved." Low cost items were also often regarded as low risk because of the cost of the service or product.

On the other hand, one participant did mention she had trust concerns when buying free or low cost items. P13 only downloaded free applications for her mobile device, but instead of seeing this as little risk she saw it as a potential invasion of privacy. The participant explains her concern:

"I briefly thought about how (the app) now knows about some of the types of music I listen to, after I played a song for the app and they offered me ringtones. Will they now try and market similar types of music/lifestyle products to me?" And during another free download purchase the participant mentions "(it) made me think if this information (is) being accessed and used for marketing."

While seemingly mundane, the above findings show that when people think about 'trust' in their mCommerce activities, they mostly think about loss of money. Because the cost of many items (e.g., apps for their devices) is low or free, they do not feel trust is a concern. Yet there are certainly many other issues that could arise and pose trust issues for mobile shopping and purchasing such as the reveal or surreptitious use of personal information (e.g., credit card information), the tracking of one's browsing activities, the tracking of one's purchases, poor quality of service, etc. P13's comments begin down this path; however, this line of thinking was rare amongst participants.

When items were expensive, participants never mentioned a heightened level of trust. Instead they would just comment on the cost being too expensive. One participant, who bought car insurance, a $\$ 550$ purchase, indicated she would have had no problem ordering over her mobile device but the company would not allow her to do so. Instead, she had to migrate from shopping on her phone to purchasing on her computer.

\section{Product and Store Brands}

Aside from simply a lack of risk due to little money being exchanged, 'brand' played the most significant role in trust for mCommerce. By brand we are referring to the actual company that participants engaged with to shop or make purchases (e.g., the eBay app, the Macy's web page). Participants continually stressed their trust in these brands either as a marketplace app or the actual vendor. Only one participant recorded diary entries, which, excluding price comparison activity, had no past experience with the vendor. Some comments around large well-known brands included:

"Amazon is a trustworthy site" - P10

"eBay is a trusted company"- P15

"(Macy's) are the most reputable big department retail store in the U.S., so in terms of security, if that fails I don't know who to trust then" - P10

"[the] Apple App store is an official app for Apple brand and since Apple is a famous brand so I have no problem trusting and purchasing online with them." - P8

In cases where participants had negative feelings towards a brand, the company's app was never downloaded to the person's mobile device. Participants simply knew the companies before they would shop at their stores (via the store's app) on their mobile device.

Several participants commented that they repeatedly purchased from the same places and this history made them feel safer and lead to them trusting the company and their activities with it. When it came to first time shopping with a particular company, participants relied on other indicators to increase the level of trust they felt. These included the overarching approval process of many mCommerce applications and relying on the recommendations of others; we discuss these in the next two sections.

\section{Brand Transfer through the 'App' Approval Process}

In addition to trust in store and product brands themselves, participants mentally transferred their trust from larger companies (e.g., Apple) that approved mCommerce applications to the applications themselves. That is, app marketplaces were highly successful in transferring trust from their well-known brands-Android App Market, Amazon's marketplace, Apple's iTunes, and the Apple App 
Store - to their affiliates and partners. For example, if participants were using an app on their mobile device for shopping, regardless of which company made the individual app, because the app had been approved through a larger trusted company (e.g., Apple), the trust the participant had with that company transferred to the app itself. A similar phenomenon occurred for purchasing or downloading apps themselves. Because apps were approved by a larger, trusted company, apps themselves were considered to be trustworthy.

For example, many participants said that apps found in the Apple store were trustworthy because, as consumers, they felt they were protected by the Apple brand and the 'prescreening' that the company does before permitting an app to be present in the store.

"everything is prescreened in the (Apple) app store, so there is no worry about (trust)". - P1

"it just feels like a more cohesive thing when it is under that one umbrella company of Apple... [not using the app store] just feels like you are opening up your phone to all the internet and random companies". - P4

"It was through iTunes so I didn't have any trust issues... I trust the iTunes brand and I believe they really check the quality in products before they release them ..." - P17

We also found that in some cases participants were not even conscious of the mental transfer of trust between brands in this way. For example, during some interviews, participants would first claim that they would not download an app without knowing the company who created it or offered it. However, in subsequent interview questions, they admitted to doing just that.

\section{Recommendations from Friends or Family Members}

We also found that participants had few trust concerns because many of their shopping or purchasing activities were based on recommendations by close friends or family. For example, 9 of the 17 participants engaged in mCommerce activities that were initiated by a friend or family member's recommendation, either in person or via an electronic medium (e.g., email). Within these nine, four even engaged in a mCommerce activity directly through a social media platform (e.g., Twitter, Facebook).

The times of items and stores that people received recommendations on varied heavily. For example, P1 downloaded a sports team app for her mobile phone based on a friend's recommendation, $\mathrm{P} 2$ downloaded a recipe from a recipe site recommend by her partner, P9 shopped for racquets based on the recommendations of her friend, a tennis 'pro,' and P13 bought frozen yogurt based on a friend's recommendation. Perhaps the most self-aware of the influence that friends had on his shopping was P17 who said, "I have a whole shopping network... me and my friends all use Groupon."
Because of the social influence of others, interactions with particular vendors or products were deemed to be trustworthy, regardless of whether they actually were or not in fact. The sheer act of social recommendation elevated companies, brands, or items to a trustworthy status.

In most cases, social recommendations were just from close friends or family members, yet they did sometimes come from strangers where a person would rely on them if there was a large response from people:

"The seller has 100\% positive feedback on eBay and I don't buy from sellers that [have] neutral or negative feedbacks" - P15

\section{Mistrust}

In some cases, mistrust did arise but this was rare. Across all 161 diary entries, only 11 entries indicated there was a trust issue. The reasons for why the participants had trust issues often related to the previously discussed reasons for assuming trustworthiness.

Social Recommendations. Four diary entries discussed a lack of trust in the purchasing of a mobile device app because the app had a low rating as recommended by other users. In only one case did the participant continue on to downloading the app. Another participant commented "I decided not to download even the free version because the comments were all negative." Together, this further suggests that even if a person doesn't receive advice or recommendations from people they know, if there is a large enough response, they will rely on the advice of strangers.

Brand. In total, four diary entries related to mistrust because of brand. Two diary entries by the same participant reflected instances where he simply did not trust a brand because of a lack of recent history with it. When asked if he had trust issues, he told us in the first case, "yes, as I have not purchased on this site before," and, in the second case, "yes because I haven't ordered flowers for a long time and I couldn't remember what website I had used before." In addition to this, we saw two more diary entries where the brand (the company) was not trusted because of the company's location; one was located in Hong Kong and one was in England, which are both a long distance away from the participant.

Hard Trust Issues. Two diary entries related to hard trust concerns. One participant was concerned about a potential virus, while another was worried about the security of the wireless network they were on in a mall.

Other Reasons. In addition to the above, participants cited usability issues ( 1 entry) and the limited ability to physically evaluate a product ( 1 entry) as reasons to mistrust mCommerce activities.

Even though the frequency of the above occurrences is small, it further suggests the importance of the aforementioned reasons why people have few trust concerns for their mCommerce activities. 


\section{DISCUSSION}

The purpose of our study was to explore people's mCommerce routines and activities, identify how people think about trust during these activities, and understand how trust affects their shopping and purchasing behaviours. We now turn to a discussion of our results and reflect back on the related work for mobile device usage along with theories of trust.

\section{Mobile Device Usage}

First, our work builds on the related work of mobile device usage. We now know that mCommerce activities occur in a variety of locations, including the home, public transit, and, to a lesser extent, at work. This more specifically builds on Nylander et al.'s location classification for mobile device usage [15] and shows that people turn to their mobile devices for shopping even if computers are located close by. This is because a large amount of mCommerce activities relate to purchases for the mobile device itself, but also because people simply have a preference for shopping in this way. Like the consumption of mobile video and video telephony services [16,17], mCommerce activities also occur in public spaces like transit commutes where the act of shopping represents a private activity in a more public space. We also have found that shopping activities typically stay on the mobile device with little concern about migrating the activity to other computers or devices; this contrasts Karlson et al.'s [7] findings about email-based activities. Palen et al. [19] showed that mobile phones are very much social devices; we extend this to show the impact of social recommendations on mobile shopping activities and trust. Similar to O'Hara and Perry's results [18], we too saw social collaboration as a major theme in user behaviour. However, in our study, social collaboration was just as much a catalyst to spontaneous purchases as a deterrent [18]. Furthermore, we found no participants partook in mCommerce activities that originated from interruptive marketing efforts via mobile, print or television advertising, which is a new finding.

There are certainly many possible design implications from these shopping behaviors. At the most basic level, they suggest that mobile shopping designs could be created to target users based on these routines (or lack of) and optimize their experience. For example, 'fixed time' shoppers could be detected based on their pattern of usage and provided with a more 'browsing'-like experience to fill their time. We encourage others to continue to build on this paradigm of design suggestions and use our study findings as a basis for additional design work.

\section{Trust in mCommerce Activities}

Our work has also illustrated the ways that trust is thought about by people participating in mCommerce activities and how trust concerns are largely mitigated.

First, Zucker [25] developed three trust mechanismscharacteristic-based, process-based, and institutional-based trust - that have been used as a lens for eCommerce trust
[8]. If we look at these mechanisms in relation to our findings about mCommerce, we see how some of them continue to play a significant role in establishing consumer trust. However, the fulfillment of these mechanisms often took on a new form that was specific to mCommerce when compared to eCommerce or traditional retail shopping.

Characteristic-Based Trust. Characteristic-based trust refers to trust that is developed through similarities between consumers and companies (e.g., similar gender, ethnicities, affiliations) $[8,25]$. In age of mobile shopping, devoid of much human contact (at least between company employees and consumers), one might think that it would be hard to establish trust in this way. Yet, as our results showed, many participants engaged in mCommerce activities that were initiated by a friend or family member's recommendation. Because of the social recommendation, people placed trust in a site, service, or product, regardless of whether or not it was trustful. Thus, having friends, family, or, to a lesser extent, social networks provide recommendations for shopping makes characteristic-based trust a key component for mCommerce trust.

This is promising for companies; however, if one thinks about targeted advertising, consumers face a challenging future where it will be increasingly difficult to know if social recommendations are valid. For example, social networking sites (e.g., Facebook) are increasingly placing advertising amongst information about one's friends and family. The mere placement of such information in close proximity to one's trusted social network may easily suggest a false sense of security for mCommerce activities.

Process-Based Trust. For process-based trust-trust that is built through a history of past transactions $[8,25]$ - we see that even though participants were experiencing a new medium for shopping (e.g., mobile shopping), they brought notions of trust with them through their prior experiences with eCommerce and retail experiences. For example, they continued to shop with companies that were previously known to them in the non-mobile space, such as eBay, Amazon, etc. For companies that are designing applications to support mCommerce, this suggests that designers should fully integrate their mobile commerce opportunities with existing commerce sites and interactions such that notions of trust will transfer. For example, a company that presents an eCommerce web presence should provide a similar mCommerce presence in look and feel where a person could easily migrate between the two. Some companies already do this to a certain extent (e.g., eBay), yet we now see and understand the importance in doing so as it relates to trust.

Institutional-Based Trust. Institutional-based trust relates to trust that is established by presenting a public presence that is respected and shows integrity [25]. This is commonly done through third-party guarantors, membership in associations with professional codes of conduct, etc. $[5,8,25]$. The definition of this type of trust 
mechanism did not historically include distribution models such as app marketplaces, yet these have in essence played the role of third party guarantors when it comes to mCommerce. That is, the (often stringent) approval processes (e.g., Apple's App Store) that mobile apps must go through before they are even placed in the hands of consumers acts as a guarantor of service or products acquired through it. This is regardless of whether or not such approval processes actually do make companies more trustworthy with their apps or shopping services. For consumers, it doesn't matter; they simply assume so.

One could argue that historically this trust role has been associated with search engines in eCommerce. Yet in mCommerce, app marketplaces have now taken over this role. While the actual creator of the app might not get the brand recognition for the experience, in the mobile space this seems to be one of the best ways for companies to get their products in the hands of potential new users. Traditional more obvious eCommerce institutional-based trust mechanisms such as third party seals and security seals were never mentioned or became apparent amongst participants.

Consumer Vulnerability. If we look at Head and Hassanein's [6] factors which make consumers vulnerable in eCommerce transactions-providing their email address, shipping information, credit card numbers, etc.-it is evident that these happen at the time of purchase. For example, a user must input detailed information in order to finalize a purchase on an eCommerce web site. Yet this does not transfer to mCommerce. As our results showed, nearly all purchases occurred through an app marketplace, which means that purchase information went through the larger trusted brand provided by the marketplace and not necessarily at the actual time of purchase. For example, when making a purchase in the Apple App Store, payment information is entered when a user first creates an Apple account. Then, when consumers decide to purchase something through the App Store, they need only enter in an account password in order to make the purchase. This type of 'automatic' payment eliminates factors of perceived vulnerability. One could compare this to the manner in which PayPal provides assurances for eCommerce.

Retail Shopping. Finally, Head and Hassanien [6] developed a set of factors that describe why it is difficult for eCommerce companies to develop trust as compared to retail stores (e.g., it's easy to create an eCommerce site, etc.). When considering mCommerce, we can see less concern when it comes to establishing a mobile shopping presence as there is typically a rigorous process to create and publish mobile apps. Our participants recognized this and felt increased trust because of it. Similarly, one could argue because of the higher barrier of entrance, having a mobile presence would be a show of longevity similar to that of a physical investment. This would be akin to consumers being able to see a retail store's investment in buildings and personnel. In the case of human interaction, our participants often relied on social recommendations and brand recognition to establish trust; this makes such interactions less of a concern for mCommerce. Yet such social recommendations could easily become problematic if they are based on minimal knowledge.

Limitations. While beneficial, we recognize that our work did not explore all routines and practices that might be experienced by mCommerce users. Our users were all periodic to regular shoppers and, as such, we did not collect any data from people who were new to mobile shopping and purchasing, or even mobile devices for that matter. It is likely the case that such individuals would have different shopping behaviours and increased trust concerns at least initially as they learn how to shop and buy on their mobile device; however, further studies are needed to explore this. Our study is limited to presenting findings on experienced, regular shoppers who have an established understanding of mCommerce and 'trust' (or mistrust) within it and moves our findings beyond more generic issues of technology adoption.

There are also potential limitations with our study methods. Participants' self-reporting and the diary's focus on mCommerce could have increased their mobile shopping activities; yet, this is likely not the case as we did not see high amounts of shopping activities. We also specifically asked participants about 'trust' (albeit very generally), which could have made them think about trust more. Given our findings, we feel responses were not biased in any significant way. The results-which showed few trust issues-are strong proof of this. There are also well documented limitations for in situ methods [2] hindering the organic experience, however, we chose our method because the benefits of users recording in the moment examples and detail were important to the study. We reduced these limitations by providing the participant with convenient ways to capture activity while under mobile and active conditions.

\section{CONCLUSION}

Our paper explored the shopping and purchasing behaviours of users on their mobile devices through a diary and interview study. Here we found that mobile commerce activities are a ubiquitous activity that occurs in many places, including home, work, and on transit. For some this spontaneous, and for others it was either part of a routine or during fixed time intervals. In relation to trust, many people had few concerns and this can be attributed to several factors that map at a high level to trust mechanisms established for eCommerce. That is, most of the trust mechanisms/factors that we saw for mCommerce could be translated in some form to those established for eCommerce. However, in each case, mCommerce brought unique nuances in terms of how the trust mechanisms were being applied and thought about by users. Our results suggest that because purchases were made on a mobile 
device, unlike personal computers, they tended to be made from companies which either already had a strong relationship with users from previous mobile transactions, those done in other mediums, or because of a strong referral by friends (or at the very least a referral in a social space). Compared to eCommerce, mCommerce seems to be more of an extension of the entire 'brand experience' and less of a starting point in an introduction to a brand. Our findings suggest that the more mCommerce applications tie to existing friend networks or established and known brands, the more likely people will trust them (for good or bad).

Perhaps the most fascinating difference between eCommerce and mCommerce activities and notions of trust was the heavy use of application stores and 'apps' designed by specific companies. The regular use of these applications is non-existent within the eCommerce literature. Of course, we are now beginning to see companies migrate many strategies from mCommerce to the eCommerce domain where computer-based shopping and purchasing can be performed in app marketplaces just like on mobile devices. For example, the Apple App Store can now be used on a Mac computer for buying software (e.g., programs, games). This suggests that commerce activities in the future will further blend between eCommerce and mCommerce. We purposely did not study shopping on computers as our focus, yet future studies should investigate how mCommerce routines translate to this new paradigm of eCommerce shopping, or vice versa.

\section{REFERENCES}

1. Amazon.com Announces Second Quarter Sales up 41\% to $\$ 6.57$ Billion, http://phx.corporateir.net/phoenix .zhtml?c=176060\&p=irolnewsArticle \&ID=1451043\&hi ghlight $=$, Accessed Sept 2011.

2. Brandt, J., Weiss, N., and Klemmer, S.K. txt 4 18r: lowering the burden for diary studies under mobile conditions. In CHI Extended Abstracts 2007,

3. Bloomberg Business Week, http://www.businessweek .com/news/2011-01-20/ebay-shares-rise-after-2011forecasts-top-estimates.html, Accessed Sept 2011.

4. comScore, July 2011 U.S. Mobile Subscriber Market Share, http://www.comscore.com/Press Events/Press Releases/2011/8/comScore_Reports_July_2011_U.S. Mobile_Subscriber_Market_Share, Access Sept 2011.

5. D.H. McKnight, V. Choudhury, and C. Kacmar, Developing and Validating Trust Measures for eCommerce: An Integrative Typology, Information Systems Research, Vol. 13, (2002), 334-359.

6. Head, M. and Hassanein, "Trust in e-Commerce: Evaluating the Impact of Third-Party Seals", Quarterly Journal of Electronic Commerce, 3(3), (2002), 307-325.

7. Karlson, A., Iqbal, S., Meyers, B. Ramos, G., Lee, K., and Tang J., Mobile Taskflow in Context: A Screenshot Study of Smartphones, Proc. CHI, ACM Press (2010).
8. Luo, X., Trust Production and Privacy Concerns on the Internet - A Framework Based on Relationship Marketing \& Social Exchange Theory, IMM, 31,(2002).

9. Lumsden, J., MacKay, L., "How Does Personality Affect Trust in B2C e-Commerce?", National Research Council of Canada, August, (2006).

10. McCabe, L., "What is Mobile Commerce, and Why Should You Care?", Small Business Computing.com, September 13, (2010).

11. Min, Q., Ji, S., and Qu G, Mobile Commerce User Acceptance Study in China: A Revised UTAUT Model, Tsinghua Science Technology, 13(3), (2008).

12. Mobile Commerce Daily, http://www.mobilecomme rcedaily.com/2011/06/27/paypal-predicts-3b-in-mobilepayments-in-2011, Accessed Sept 2011.

13. Mulpuru, S. Mobile Commerce Forecast. Forrester Research, http://forrester.com/rb/Research/mobile_com merce_forecast_2011_to_2016/q/id/58616/t/2 (2011).

14. Ngai, E.W.T., and Gunasekaran, A. A Review for Mobile Commerce Research and Applications, Decision Support Systems, 43, Elsevier (2007).

15. Nylander, S., Lundquist, T., and Andreas B. At Home and with Computer Access: Why and Where People Use Cell Phones to Access the Internet, Proc. CHI, (2009),

16. O'Hara, K., Black, A., and Lipson, M. Everyday Practices with Mobile Video Telephony, Proc. CHI, ACM Press (2006).

17. O'Hara, K., Mitchell, A., and Vorbau, A. Consuming Video on Mobile Devices, Proc. CHI, ACM (2007).

18. O'Hara, K., and Perry, M., Shopping Anytime Anywhere, Extended Abstracts Proceedings of the ACM CHI 2001, p. 345-346 (2001).

19. Palen, L., Salzman, M., and Youngs, E. Going Wireless: Behavior \& Practice of New Mobile Phone Users, Proc. $C S C W$, ACM Press (2000).

20. Stafford, T., Gillenson. M, Mobile Commerce: What It Is and What It Could Be, Communications of the ACM, 46(12), ACM Press (2003).

21. Strauss, A. and Corbin, J. Basics of Qualitative Research, 2nd Edition, Sage Publications (1998).

22. Tammienen, S., Oulasvirta, A., Toiskallio and Kankainen, A., Understanding Mobile Contexts. Personal \& Ubiquitous Computing, Springer (2004).

23. Tauber, E., "Marketing Notes and Communication: Why Do People Shop?", Journal of Marketing, 36, (1972).

24. Tiwari, R. and Buse, S., The Mobile Commerce Prospects, Hamberg University Press, pp. 30-31, (2008).

25.Zucker L. Production of Trust: Institutional Source of Economic Structure: 1804-1920, Research in Organizational Behavior, 8, JAI Press (1986), 53-11. 